\title{
Review \\ The role of cytokines in regulating estrogen synthesis: implications for the etiology of breast cancer
}

\author{
Atul Purohit, Simon P Newman and Michael J Reed
}

Faculty of Medicine, Imperial College, St Mary's Hospital, London, UK

Correspondence: Professor MJ Reed, Endocrinology and Metabolic Medicine, Faculty of Medicine, Imperial College, St Mary's Hospital, London, W2 1NY, UK. Tel: +44 0207886 1738; fax: +44 0207886 1790; e-mail: m.reed@ic.ac.uk

Received: 15 October 2001

Breast Cancer Res 2002, 4:65-69

Revisions requested: 19 November 2001

Revisions received: 26 November 2001

Accepted: 29 November 2001

Published: 14 January 2002

\author{
(C) 2002 BioMed Central Ltd \\ (Print ISSN 1465-5411; Online ISSN 1465-542X)
}

\begin{abstract}
Cytokines, such as IL-6 and tumor necrosis factor (TNF)- $\alpha$, have an important role in regulating estrogen synthesis in peripheral tissues, including normal and malignant breast tissues. The activities of the aromatase, estradiol $17 \beta$-hydroxysteroid dehydrogenase and estrone sulfatase are all increased by IL- 6 and TNF- $\alpha$. Prostaglandin $\mathrm{E}_{2}$ may also be an important regulator of aromatase activity in breast tumors. Macrophages and lymphocytes, which invade many breast tumors, are thought to be an important source of factors that can stimulate estrogen synthesis in malignant breast tissues. The coordinated stimulation of the activities of the enzymes that are involved in estrogen synthesis offers an explanation for the high concentrations of estrogens that are present in breast tumors.
\end{abstract}

Keywords: aromatase, breast cancer, cytokines, estrogens, estrone 17ß-hydroxysteroid dehydrogenase, estrone sulfatase

\section{Introduction}

Considerable advances have been made in recent years in understanding the genetics and molecular biology of breast cancer, but for women in most western countries, breast cancer still remains a major cause of death. The majority of breast tumors are initially dependent upon estrogen to support their growth, with the highest incidence of breast cancer occurring in postmenopausal women at a time when ovarian production of estrogens has ceased. In this group of women estrogens continue to be produced in extraglandular (i.e. non-ovarian) sites, such as adipose tissue [1] but also in normal and malignant breast tissues [2]. There is now convincing evidence from a number of studies that concentrations of the biologically active estrogen, estradiol, are higher in malignant than in normal breast tissue [3,4]. Furthermore, the levels of estradiol that are detected in breast tumors are 50 to 100 -fold higher than the concentrations of this hormone that are found in the circulation of postmenopausal women.

The high estradiol concentrations found in breast tumors could arise either due to uptake from the circulation or from in situ synthesis. As similar concentrations of estradiol are present in tumors with or without estrogen receptors, in situ synthesis is now considered to be the major pathway by which tumor estrogens originate. In this paper we review the evidence implicating cytokines, and other factors, in regulating the activities of the enzymes that are involved in estrogen synthesis in breast tissues. The identification of cytokines as having a critical role in regulating estrogen synthesis in peripheral tissues has suggested mechanisms by which some known risk factors for breast cancer (e.g. obesity, stress) may act to increase estrogen synthesis within the breast.

$17 \beta-H S D=$ estradiol $17 \beta$-hydroxysteroid dehydrogenase; DHEA-S = dehydroepiandrosterone sulfate; E1-STS = estrone sulfatase; IL = interleukin; $\mathrm{P}=$ promoter; $\mathrm{PGE}_{2}=$ prostaglandin $\mathrm{E}_{2} ; \mathrm{Th}=\mathrm{T}$ helper cell; $\mathrm{TNF}=$ tumor necrosis factor. 


\section{Estrogen synthesis in normal and malignant breast tissues}

Three main enzyme complexes are involved in the synthesis of estrogens in peripheral tissues: aromatase is responsible for the aromatisation of androstenedione to estrone; estrone sulfatase (E1-STS) catalyses the formation of estrone from estrone sulfate; and estradiol-17 $\beta$-hydroxysteroid dehydrogenase (17 $\beta$-HSD) Type 1 is responsible for the reduction of estrone to the biologically active estrogen, estradiol. In addition, other enzymes, including 17 $\beta$-HSD Type 2 which inactivates estradiol, and estrone sulfotransferase, which renders estrogens inactive through sulfate conjugation, are also important in regulating the tissuespecificity and ligand availability of estrogenic hormones.

\section{Aromatase}

The aromatase enzyme, CYP19 P450 (AROM), belongs to a family of P450 enzymes [5]. In post menopausal women it is located mainly in adipose tissue but is also present in normal and malignant breast tissues. Immunocytochemical studies to examine the location of aromatase in breast tumors have provided evidence for a stromal [6] and epithelial location [7]. Measurements of aromatase activity in fibroblasts derived from breast tumors or MCF-7 cells, however, have revealed a much higher level of aromatase activity in fibroblasts [8].

Aromatase activity in breast tissues is relatively low, and there has been considerable debate as to whether sufficient estrogen could be produced to evoke a biological response (i.e. stimulate tumor growth). Studies in women with breast cancer revealed, in fact, that a major proportion of breast tumor estrogen is synthesized in situ [9] and that this is almost completely abolished by the potent aromatase inhibitors that are now in clinical use [10].

A breakthrough in understanding the control of aromatase activity in breast cancer was made by Miller and colleagues [11]. They were the first to show that the location of a tumor within the breast influenced aromatase activity in the quadrant in which the tumor was located. This finding, which was subsequently confirmed at the expression and activity levels, suggested either that tumors developed in an area of high aromatase activity within the breast or that tumors were capable of producing factors that stimulated aromatase activity in adjacent tissues. Over the last decade many studies have been carried out to identify potential aromatase stimulatory factors. The analysis of breast cyst fluid initially led to the identification of several factors that could stimulate aromatase activity; IL-6 was the most potent factor detected [12]. Cultured fibroblasts derived from normal or malignant breast tissue were also found to be a rich source of IL-6. The ability of IL-6 to stimulate aromatase activity was subsequently shown to be markedly potentiated by the IL-6 soluble receptor [13]. This soluble receptor is produced by fibroblasts from malignant, but not normal, breast tissue, malignant breast epithelial cells and cells of the immune system [13]. Other cytokines and growth factors that can stimulate aromatase activity include TNF- $\alpha$, oncostatin $M$, leukaemia inhibitory factor and insulin-like growth factor Type I [14].

The aromatase gene is expressed in several tissues in the body (e.g. ovary and placenta) in addition to peripheral tissues. It is now known that expression of the aromatase gene is regulated in a tissue-specific manner by the use of alternative promoters [15]. In adipose tissue its expression is regulated mainly from promoter (P) I.4; PII and PI.3 have lesser roles [16]. The $5^{\prime}$-upstream region of $\mathrm{Pl} .4$ contains a glucocorticoid response element and an IFN- $\gamma$ activating sequence element which can bind transcription factors of the 'signal transducer and activator of transcription' family [17]. Cytokines, in the presence of glucocorticoids, regulate aromatase gene expression via the Pl.4. In malignant breast tissue the important observation was made that promoter switching occurred such that aromatase gene expression is regulated by PII and PI.3 to a greater extent than PI.4 [18,19]. Expression from PII and PI.3 is regulated by CAMP and factors that regulate CAMP levels. Prostaglandin $E_{2}\left(P E_{2}\right)$ is thought to be an important regulator of aromatase gene expression via $\mathrm{PII}$ and $\mathrm{PI} .3$ [20]. Although the mechanism by which promoter switching in malignant breast tissue occurs remains to be elucidated, it is likely that the use of alternative promoters confers a growth advantage on the tumor. Studies are currently in progress to determine the relative abilities of IL- 6 and $\mathrm{PGE}_{2}$ to simulate aromatase activity in fibroblasts derived from normal and malignant breast tissues. Regulation of aromatase activity in malignant tissues, however, is likely to be highly complex. It has recently been found that $\mathrm{PGE}_{2}$ may act, at least in part, by stimulating IL-6 production in fibroblasts derived from normal and malignant breast tissues [21].

\section{Estrone sulfatase}

Much of the estrone derived from androstenedione is converted to estrone sulfate by estrone- and phenol-sulphotransferases. Estrone sulfate is hydrophilic and circulates at much higher levels than that of the unconjugated estrogens and acts as a reservoir for the formation of active steroids via the action of estrone sulfatase (E1-STS). Expression of E1-STS mRNA is much higher in malignant than in normal breast tissue [22]. The determination of E1-STS mRNA expression in breast tumors has prognostic significance and a high level of expression is associated with a poor prognosis [23].

E1-STS belongs to a family of 11 sulfatase enzymes but only one steroid sulfatase is thought to exist which is able to hydrolyse both aryl (e.g. estrone sulfate) and alkyl (e.g. dehydroepiandrosterone sulfate [DHEA-S]) substrates. Recently DHEA-S was shown to be a potent stimulator of 
the growth of MCF-7 breast cancer cells [24]. The DHEA$S$ stimulated growth of these cells could not be blocked by aromatase inhibitors. This finding provides convincing evidence for an alternative pathway by which the growth of hormone-dependent tumors might be stimulated. DHEA-S is converted to DHEA, by steroid sulfatase, and DHEA can be subsequently reduced to androstenediol, a steroid with potent estrogenic properties.

Research into the regulation of E1-STS expression and activity is still in its infancy. While cytokines such as IL-6 and TNF- $\alpha$ can increase the activity of this enzyme, no effect of these cytokines at the expression level has so far been detected [25]. Thus, these cytokines may act to increase post-translational modifications of the enzyme. Alternatively, it has been postulated that IL- 6 and/or TNF- $\alpha$ may affect membrane permeability, thereby increasing substrate availability and hence enzyme activity.

\section{Estradiol-17 $\beta$-hydroxysteroid dehydrogenase Type 1}

Estrone can be formed as a result of aromatase or E1-STS activity but to achieve its full biological potency it must be reduced to estradiol; this reaction is mediated by $17 \beta$ HSD Type 1. There are 9-10 members of the 17 $\beta-H S D$ family of enzymes, which regulate ligand availability to either the estrogen or androgen receptors [26]. Other reactions catalysed by members of the $17 \beta-H S D$ family include the reduction of DHEA to androstenediol (Types 1 and 5), androstenedione to testosterone (Types 3 and 5) and the inactivation of estradiol (mainly Type 2).

When high estradiol concentrations were initially detected in breast tumors it was not readily apparent why such high levels should exist in tumors. The overall peripheral metabolism of estrogens strongly favors the inactivation of estradiol rather than the conversion of estrone to estradiol. Using an isotopic infusion technique in women with breast cancer, estrone was found to be preferentially converted to estradiol in tumor tissue [27]. A search for factors that could preferentially stimulate the conversion of estrone to estradiol identified IL- 6 and TNF- $\alpha$ as key regulators $[28,29]$. In addition, insulin-like growth factor Type I and an albumin-like molecule isolated from breast tumor cytosol, were also found to regulate the conversions of estrone to estradiol [30]. In MCF-7 breast cancer cells most cytokines and other factors have been found to preferentially stimulate the conversions of estrone to estradiol. In another breast cancer cell line, ZR-75-1, IL-4 and IL-6 were found to markedly stimulate the inactivation of estradiol, thus the effects of cytokines on $17 \beta-H S D$ activity vary in different cell lines [31]. However, in view of the increased conversion of ${ }^{3} \mathrm{H}$ estrone to ${ }^{3} \mathrm{H}$ estradiol detected in breast tumors [9] and the high estradiol concentrations in tumors [3,4], it would appear that overall cytokines must act in vivo to stimulate estrogen synthesis.

\section{Co-ordination of breast tumor estrogen synthesis}

It is now evident that cytokines, growth factors and $\mathrm{PGE}_{2}$ have crucial roles in regulating estrogen synthesis in breast tumors. IL- 6 and TNF- $\alpha$ can stimulate the activities of all the enzymes involved in estrogen synthesis; $P \mathrm{PE}_{2}$ is important in regulating aromatase gene expression in malignant tissues (Fig. 1). It is likely that the activities of the aromatase, E1-STS and estradiol dehydrogenase Type 1 are increased in a co-ordinated manner by the actions of cytokines and $\mathrm{PGE}_{2}$. Such a mechanism may account for the high concentrations of estradiol that are detected in breast tumors.

\section{Origin of cytokines}

The important role that cytokines have in regulating breast tumor estrogen synthesis stimulated research into the origin of such factors. There is convincing evidence that IL- 6 is produced by fibroblasts derived from normal and malignant breast tissues. Conditioned medium collected from lipopolysaccharide-stimulated monocytes and lymphocytes was also found to markedly stimulate aromatase activity in breast-tissue-derived fibroblasts [8]. This finding suggests that these cells may be an important source of stimulatory cytokines.

Recent studies by Daynes [32] and Rook [33] have investigated factors involved in regulating cytokine production by Th cells. Their studies have suggested that the balance of the adrenal androgen, DHEA, to that of glucocorticoids determines the type of cytokines produced by Th lymphocytes. Th cells can progress to either a Th1 or Th2 phenotype and each type of Th cell secretes a characteristic profile of cytokines; IL-6 is produced by Th2 cells. High levels of DHEA are associated with a Th1 response while a predominantly glucocorticoid environment promotes a Th2type response. Production of DHEA starts to decline at about the age of 25 years and thus in older subjects there is a switch from a Th1- to Th2- type of environment. IL-4 is a Th2-type cytokine and has been shown to induce 33HSD/isomerase activity in breast cancer cells which increases the conversion of DHEA to androstenedione [31]. As androstenedione is a substrate of the aromatase, this could be another mechanism by which cytokines increase estrogen synthesis in breast tumors. Activation of the immune response and inflammation may also support tumor formation by inducing a Th2-type response [34]. In addition to the role that IL-6 has in stimulating estrogen synthesis, it is also a pro-angiogenic factor, supporting the growth of new blood vessels that are essential for tumor growth.

\section{Implication for the etiology of breast cancer}

The identification of cytokines as having an important role in regulating estrogen synthesis in breast tissues has provided new insight into understanding some aspects of the etiology of breast cancer. It is well established that breast 


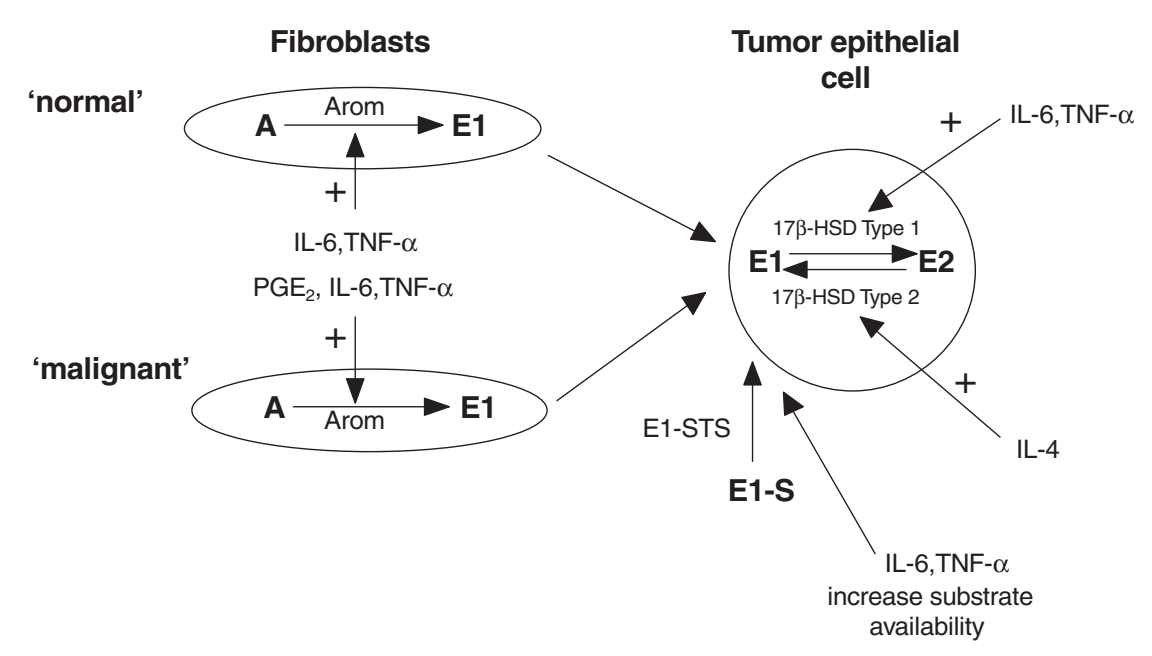

Estrogen synthesis in breast tissues. Three enzyme complexes are involved in estrogen synthesis in breast tissues: (1) Aromatase (Arom) which converts androstenedione (A) to estrone (E1); (2) estrone sulfatase (E1-STS) which hydrolyses estrone sulfate (E1-S) to E1 and (3) estradiol-17 $\beta$ hydroxysteroid dehydrogenase (17 $\beta$-HSD) Type 1 which reduces E1 to the biologically active estrogen, estradiol (E2). 17 $\beta$-HSD Type 2 is involved in the inactivation of E2. Higher levels of aromatase activity are detected in stromal fibroblasts. In 'normal' breast tissue, aromatase gene expression is thought to be regulated to a greater extent by promoter (P)I. 4 expression, which is stimulated by cytokines such as IL-6 and tumor necrosis factor (TNF)- $\alpha$. In malignant breast tissues, aromatase gene expression is thought to be regulated to a greater extent by PI.3 and PII, expression of which is stimulated by cAMP and factors such as prostaglandin (PG) $E_{2}$, which increase cAMP levels. Cytokines such as IL-6 and TNF- $\alpha$ also increase $17 \beta$-HSD Type 1 activity, while their effect on E1-STS activity may be indirect.

cancer occurs more frequently in older, postmenopausal women and that obese postmenopausal women are at an increased risk of developing breast cancer. Several studies have now shown that plasma IL-6 levels increase with aging [35]. It is possible that the decrease in DHEA production that occurs with aging induces a Th2-type cytokine response that is associated with increased production of IL-6. There is also evidence that production of IL- 6 and TNF- $\alpha$ may be influenced by body weight [36]. The peripheral conversion of androstenedione to estrone is increased in older, overweight subjects. It is now apparent that changes in cytokine production that are related to obesity and aging, by increasing aromatase, E1-STS and estradiol dehydrogenase Type 1 activities, may account for the increased peripheral production of estrogens in such subjects. Although controversial, there is evidence that stress may also increase the risk of developing breast cancer [37]. By increasing glucocorticoid production, stress favors a Th2-type cytokine production and an increase in IL-6 levels. The incidence of breast cancer is reduced in immunosuppressed women [38]. As cytokine production is also reduced in immunosuppressed women, this finding supports the concept that cytokines have an important role in breast cancer, possibly acting via stimulation of estrogen synthesis $[39,40]$.

\section{Conclusion}

A major stimulus to identifying the factors that regulate estrogen synthesis in breast tumors is the insight that such knowledge may aid the development of novel drugs for the prevention or treatment of breast cancer. Preliminary investigations have already revealed that it may be possible to use small peptides or IL-6 variants to block the ability of IL-6 to stimulate aromatase activity. If the adrenal androgen, DHEA, does have an important role in regulating the Th1:Th2 balance it would seem appropriate to examine whether the administration of this steroid can be used to promote a Th1 response. Alternatively, it may prove feasible to devise an immunisation strategy that would favor a Th1-type response. In view of the relatively short-term responses for most current therapies, the development of such novel strategies may offer new hope for the treatment of breast cancer.

\section{References}

1. Ackerman GE, Smith ME, Mendelson CR, MacDonald PC, Simpson ER: Aromatization of androstenedione by human adipose tissue stromal cells in monolayer culture. J Clin Endocrinol Metab 1981, 53:412-417.

2. Miller WR, Forrest APM: Oestradiol synthesis from C19 steroids by human breast cancer. Br J Cancer 1974, 33:16-18.

3. Bonney RC, Reed MJ, Davidson K, Beranek, PA, James VHT: The relationship between $17 \beta$-hydroxy-steroid dehydrogenase activity and oestrogen concentrations in human breast tumours and in normal breast tissue. Clin Endocrinol 1983, 19:727-739.

4. Blankenstein MA, Maitimu-Smeele I, Donker GH, Daroszewski J, Milewicz A: On the significance of in situ production of oestrogens in human breast cancer tissues. J Steroid Biochem Mol Biol 1992, 41:891-896

5. Simpson ER, Ackerman GE, Smith ME, Mendelson CR: Estrogen formation in stromal cells of adipose tissue of women: induction by glucocorticoids. Proc Natl Acad Sci USA 1981, 78:56905694. 
6. Sasano H, Harada N: Intratumoral aromatase in human breast, endometrial and ovarian malignancies. Endocr Rev 1998, 19: 593-607.

7. Esteban JM, Warsi Z, Haniu M, Hall P, Shively JE, Chen S: Detection of intratumoral aromatase in breast carcinomas. $\mathrm{Am} J$ Pathol 1992, 140:337-343.

8. Singh A, Purohit A, Duncan L, Mokbel K, Ghilchik MW, Reed MJ: Control of aromatase in breast tumours: the role of the immune system. J Steroid Biochem Mol Biol 1997, 61:185192.

9. Reed MJ, Owen AM, Lai LC, Coldham NG, Ghilchik MW, Shaikh NA, James VHT: In situ oestrone synthesis in normal breast and breast tumour tissue: effect of treatment with 4-hydroxyandrostenedione. Int J Cancer 1989, 44:233-237.

10. Miller WR: Biology of aromatase inhibitors: Pharmacology/endocrinology within the breast. Endocr-Relat Cancer 1999, 6:187-195.

11. Miller WR, O'Neill JS: The importance of local synthesis of estrogen within the breast. Steroids 1987, 50:537-547.

12. Reed MJ, Coldham NG, Patel SR, Ghilchik MW, James VHT: Interleukin-1 and interleukin-6 in breast cyst fluid: their role in regulating aromatase activity in breast cancer cells. J Endocrinol 1992, 132:R5-R8.

13. Singh A, Purohit A, Wang DY, Duncan LJ, Ghilchik MW, Reed MJ: IL-6sR: release from MCF-7 breast cancer cells and role in regulating peripheral oestrogen synthesis. J Endocrinol 1995, 147:R9-R12.

14. Zhao Y, Nichols JE, Bulnn SE, Mendelson CR, Simpson ER: Aromatase P450 gene expression in human adipose tissue. $J$ Biol Chem 1995, 270:16449-16457.

15. Simpson ER, Mahendroo MS, Means GD, Kilgore MW, Hinshelwood MM, Graham-Lorence S, Amarneh B, Ito Y, Fisher CR, Michael MD, Mendelson CR, Bulun SE: Aromatase cytochrome P450, the enzyme responsible for estrogen biosynthesis. Endocr Rev 1994, 15:342-355.

16. Mahendroo MS, Mendelson CR, Simpson ER: Tissue-specific and hormonally controlled alternative promoters regulate aromatase P450 gene expression in human ovary and fetal tissue. J Biol Chem 1993, 268:19463-19470.

17. Zhao $\mathrm{Y}$, Mendelson $C R$, Simpson ER: Characterisation of the sequences of the human CYP19 (aromatase) gene that mediate regulation of glucocorticoids in adipose stromal cells and fetal hepatocytes. Mol Endocrinol 1995, 9:340-349.

18. Agarwal V, Bulun SE, Leitch M, Rohrich R, Simpson ER: Use of alternative promoters to express the aromatase P450 (CYP19) gene in breast adipose tissues of cancer-free and breast cancer patients. J Clin Endocrinol Metab 1996, 81:3843-3849.

19. Harada N, Utsumi T, Takagi Y: Tissue-specific expression of the human aromatase cytochrome $\mathrm{P} 450$ gene by alternative use of exons 1 and promoters, and switching of tissue-specific exons 1 in carcinogenesis. Proc Natl Acad Sci USA 1993, 90:11312-11316.

20. Zhao Y, Agarwal VR, Mendelson CR, Simpson ER: Estrogen biosynthesis proximal to a breast tumour is stimulated by $\mathrm{PGE}_{2}$ via cyclic AMP leading to activation of promoter II of the CYP19 (aromatase) gene. Endocrinology 1996, 137:57395742.

21. Singh A, Purohit A, Ghilchik MW, Reed MJ: The regulation of aromatase activity in breast fibroblasts: the role of interleukin-6 and prostaglandin $\mathrm{E}_{2}$. Endocr-Relat Cancer 1999, 6: 139-147.

22. Utsumi T, Yoshimura N, Takeuchi S, Maruta M, Maeda K, Harada $\mathrm{N}$ : Elevated steroid sulfatase expression in breast cancer. $J$ Steroid Biochem Mol Biol 2000, 73:141-145.

23. Utsumi T, Yoshimura N, Takeuchi S, Ando J, Maruta M, Maeda K, Harada N: Steroid sulfatase expression is an independent predictor of recurrence in human breast cancer. Cancer Res 1999, 59:377-381.

24. Purohit A, Dauvois S, Parker MG, Potter BVL, Williams GJ, Reed $\mathrm{MJ}$ : The hydrolysis of oestrone sulphate and dehydroepiandrosterone sulphate by human steroid sulphatase expressed in transfected COS-1 cells. J Steroid Biochem Mol Biol 1994, 50:101-104.

25. Newman SP, Purohit A, Ghilchik MW, Potter BVL, Reed MJ: Regulation of steroid sulphatase expression and activity in breast cancer. J Steroid Biochem Mol Biol 2000, 75:259-264.
26. Luu-The V: Analysis and characteristics of multiple types of human 17ß-hydroxysteroid dehydrogenase. J Steroid Biochem Mol Biol 2001, 76:143-151.

27. McNeill JM, Reed MJ, Beranek PA, Bonney RC, Ghilchik MW, Robinson DJ, James VHT: A comparison of the in vivo uptake and metabolism of ${ }^{3} \mathrm{H}$-oestrone and ${ }^{3} \mathrm{H}$-oestradiol by normal breast and breast tumour tissue in postmenopausal women. Int J Cancer 1986, 38:205-212.

28. Adams EF, Rafferty B, White MC: Interleukin- 6 is secreted by breast fibroblasts and stimulates $17 \beta$-oxidoreductase activity in MCF-7 breast cancer cells: possible paracrine regulation of 17ß-oestradiol levels. Int J Cancer 1991, 49:118-121.

29. Duncan LJ, Coldham NG, Reed MJ: The interaction of cytokines in regulating oestradiol 17 $\beta$-hydroxysteroid dehydrogenase activity in MCF-7 cells. J Steroid Biochem Mol Biol 1994, 49: 63-68.

30. Singh A, Blench I, Morris HR, Savoy L-A, Reed MJ: Synergistic interaction of growth factors and albumin in regulating estrogen synthesis in breast cancer cells. Mol Cell Endocrinol 1992, 85:165-173.

31. Simard J, Gingras S: Crucial role of cytokines in sex steroid formation in normal and tumoral tissues. Mol Cell Endcrinol 2001, 171:25-40.

32. Daynes RA, Araneo BA, Dowell TA, Huang K, Dudley D: Regulation of murine lymphokine production in vivo. J Exp Med 1990, 171:979-996.

33. Rook GAW, Hernandez-Pando R, Lightman S: Hormones, peripherally activated prohormones and regulation of Th1/Th2 balance. Immunol Today 1994, 15:301-303.

34. O'Byrne KJ, Dalgleish AG: Chronic immune activation and inflammation as the cause of malignancy. Brit J Cancer 2001, 85:473-483

35. Wei J, Xu H, Davies JL, Hemmings GP: Increase of plasma IL-6 concentrations with age in healthy subjects. Life Sci 1992, 51: 1953-1956.

36. Mohamed-Ali V, Goodrick S, Rawesh A, Katz DR, Miles JM, Yudkin JS, Klein S, Coppack SW: Subcutaneous adipose tissue releases interleukin- 6 but not tumour necrosis factor$\alpha$, in vivo. J Clin Endocrinol Metab 1997, 82:4196-4200.

37. Chen CC, David AS, Nunnerly H, Michell M, Dawson JL, Berry H, Dobbs J, Fahy T: Adverse life events and breast cancer. $\mathrm{Br}$ Med J 1995, 311:1527-1530.

38. Stewart T, Tsai S-CJ, Grayson H, Henderson R, Opelz G: Incidence of de-novo breast cancer in women chronically immunosuppressed after organ transplantation. Lancet 1995, 346:796-798.

39. Reed MJ, Purohit A: Breast cancer and the role of cytokines in regulating estrogen synthesis: an emerging hypothesis. Endocr Rev 1997, 18:701-715.

40. Reed MJ, Purohit A: Aromatase regulation and breast cancer. Clin Endocrinol 2001, 54:563-571. 